\title{
Elementos para uma economia política das reformas no Governo Lula
}

\author{
Elements for a political economy of \\ the reforms in Lula Government
}

EDMAR LISBOA BACHA*

\begin{abstract}
RESUMO: Sob a hipótese de que as reformas estruturais são positivas para a economia, argumenta-se que, em um governo de "direita", existe um equilíbrio estável da economia política: algumas reformas são feitas e a economia tem um desempenho mediano. Em um governo de "esquerda", esse equilíbrio mediano é instável. Uma situação de duplo equilíbrio é caracterizada: o governo ou tem sucesso total ou falha miseravelmente. A conclusão é que o sucesso do governo Lula dependerá do resultado de uma corrida entre a queda de sua popularidade, por um lado, e a melhora da economia, por outro.

PALAVRAS-CHAVE: Crescimento; direitismo; economia política; esquerdismo; reformas.
\end{abstract}

ABSTRACT: Under the hypothesis that structural reforms are positive for the economy, it is argued that, in a government of the "right", there exists stable political economy equilibrium: some reforms are made and the economy has a median performance. In a government of the "left", such median equilibrium is unstable. A situation of double equilibria is characterized: the government either succeeds fully or it fails miserably. The conclusion is that the success of Lula's government will depend on the result of a race between the drop of his popularity, on one hand, and the improvement of the economy, on the other.

KEYWORDS: Growth; rightism; political economy; leftism; reforms.

JEL Classification: E61; E65; O11; O54.

\section{MOTIVAÇÃO}

Conseguirá o governo Lula produzir um espetáculo de crescimento, uma vez aprovadas as reformas ora em análise no Congresso? Esta nota sugere uma medida de ceticismo quanto a essa possibilidade, com base em uma interpretação gráfica das interdependências entre desempenho econômico e reformas estruturais no contexto político brasileiro.

\footnotetext{
* Núcleo de Estudos de Política Econômica, Casa das Garças, Rio de Janeiro-RJ, Brasil. E-mail: ebacha@ itaubba. com.br. Submetido: agosto 2003; aceito: setembro 2003.
} 
A motivação da nota proveio da sugestão de Bolívar Lamounier de que o sucesso do governo Lula dependerá do resultado de uma corrida entre a melhoria da economia, de um lado, e a evolução de sua popularidade, de outro ${ }^{1}$.

\section{ECONOMIA RESPONDE POSITIVAMENTE ÀS REFORMAS}

Circunscrevemos a análise às possíveis relações entre o desempenho econômico e a intensidade das reformas, supondo que tudo mais permaneça constante, exceto por eventuais "choques" e "deslocamentos", discutidos nas seções 7 e 8 . A consideração das inúmeras outras variáveis, econômicas e políticas, que poderiam alterar as relações aqui consideradas nos levariam muito além dos propósitos desta nota. Para simplificarmos a exposição, trabalhamos com relações exatas, cientes, entretanto, de que, no campo da economia política, estamos discutindo relações "mais prováveis", com considerável margem de erro.

Partimos da hipótese de que há uma relação positiva entre as reformas estruturais e o desempenho macroeconômico. Quanto mais profundas forem as reformas (previdenciária, tributária, trabalhista, creditícia), melhor será o desempenho econômico.

Para fixarmos idéias, vamos supor que o desempenho econômico possa ser representado por uma única variável, que designamos por Y (sendo, por exemplo, uma combinação da taxa de crescimento do PIB ou do nível de emprego com o grau de estabilidade dos preços). Suponhamos também que a intensidade das reformas possa ser resumida numa segunda variável, que designamos por R (por exemplo, uma combinação do superávit fiscal futuro produzido pelas reformas com a redução por elas propiciadas nas distorções da alocação de recursos causadas por impostos ou a incerteza contratual). Então, Y será uma função positiva de R, conforme representada pela reta YY no Gráfico 1, onde o desempenho econômico Y está medido no eixo vertical e a intensidade das reformas $\mathrm{R}$, no eixo horizontal.

Gráfico 1: Economia - Função Positiva das Reformas

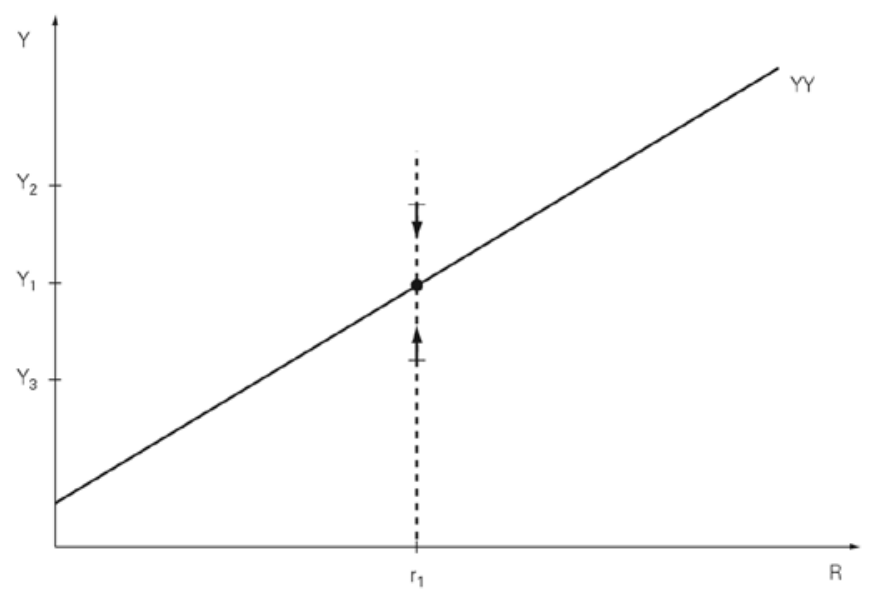


Admitamos, nesse gráfico, que a intensidade das reformas num momento dado seja igual a r1. Isto, de acordo com a reta YY, teria como contrapartida um desempenho econômico igual a y1. Para fixarmos idéias a respeito da dinâmica de ajustamento da economia à intensidade das reformas, vamos imaginar que, por alguma razão não especificada, o desempenho da economia num primeiro momento seja y2 (maior do que y1, no Gráfico 1). Então, supomos que, ao longo do tempo, a economia pioraria, conforme indicado pela seta superior na reta pontilhada saindo de r1. Se, alternativamente, no momento inicial, o desempenho econômico fosse igual a y3 (pior que y1), então, conforme indicado pela seta inferior na reta pontilhada, o desempenho da economia melhoria ao longo do tempo - sempre imaginado que a intensidade das reformas permanecesse constante em $\mathrm{r} 1$, assunto que agora passamos a considerar.

\section{REFORMAS RESPONDEM À ECONOMIA DEPENDENDO DA POLÍTICA}

Se a reação da economia às reformas é razoavelmente simples de explicitar, na política as relações são mais complicadas. Não é óbvio como o sistema político reagirá, promovendo mais ou menos reformas, em função da situação da economia. O primeiro ponto a observar é que, embora as reformas sejam boas para a macroeconomia, elas tendem, no curto prazo, a afetar negativamente interesses constituídos com força política (dentro do princípio geral de que se o jabuti está na árvore é porque alguém o colocou lá) $)^{1}$.

Para não falar da reforma da previdência, a qual é óbvia a oposição do funcionalismo público; basta lembrar, por exemplo, a reação negativa dos lobbies dos prestadores de serviços à recente proposta de mudança da incidência do Cofins e Pis-Pasep, do faturamento para o valor adicionado, com aumento das alíquotas. A proposta é boa para aumentar a eficiência da economia, pois, para uma mesma arrecadação, impostos sobre o valor adicionado são menos distorcivos da atividade econômica do que impostos sobre o faturamento. Entretanto, como a alíquota é maior, setores como o de serviços, que geram baixo crédito tributário por utilizarem poucos insumos, tendem a ser mais taxados do que antes.

O fato de reformas significativas, apesar de serem boas para a economia, por via de regra afetarem negativamente importantes grupos de interesse constituídos quer dizer que sempre haverá um importante "swing vote" em qualquer reforma proposta ao Congresso. Afora esse "centrão", passível de atração por parte do Executivo, dependendo das circunstâncias, vamos admitir que o sistema político-partidário possa ser simplificadamente dividido entre duas forças razoavelmente equilibradas politicamente; chamemo-las de "esquerda" e "direita". A "direita" tem

\footnotetext{
${ }^{1}$ Registro o inconformismo de Bolívar Lamounier quanto à licença poética no uso do velho ditado pessedista, cujas origens etimológicas expressam desconfiança: se algo inusitado está a ocorrer, deve haver intenção de alguém por trás, e não ser mero acaso.
} 
uma tendência de aderência às reformas, já que, apesar de nem sempre favorecerem interesses específicos por ela representados, as reformas favorecem o desempenho econômico como um todo dentro da ordem econômica constituída. A "esquerda" opõe-se às reformas, seja porque defende uma ordem econômica alternativa, seja porque elas afetam negativamente as corporações por ela representadas, seja porque tais reformas (dita neoliberais) têm sido uma bandeira de governos de "direita" e, portanto, eleitoralmente repudiadas pela "esquerda", na condição de oposição, dentro da lógica da disputa pelo poder.

\section{RESPOSTA DAS REFORMAS À ECONOMIA COM GOVERNO DE "DIREITA"}

Admitamos que a "direita" esteja no poder e queira promover as reformas. A “esquerda" a elas vai ser opor. A “direita” depende então do "swing vote" do centrão para fazer passar as reformas. Quanto pior estiver a economia, mais temeroso estará o centrão quanto aos riscos de subversão da ordem constituída. Portanto, mais sensível estará aos apelos do governo para votar a favor das reformas. Se, entretanto, a economia vai bem, os interesses corporativos e os temores eleitorais tenderão a prevalecer no processo decisório do centrão, opondo-se às pressões do governo para aprovar reformas "impopulares". Portanto, menos reformas serão aprovadas.

Isso quer dizer que, no caso de um governo de "direita", tende a haver uma relação negativa, que representamos pela reta $\mathrm{RD}$ no Gráfico 2, entre o desempenho econômico, $\mathrm{Y}$, e a intensidade das reformas, $\mathrm{R}$.

Gráfico 2: Reformas - Função Negativa da Economia com Governo de "Direita"

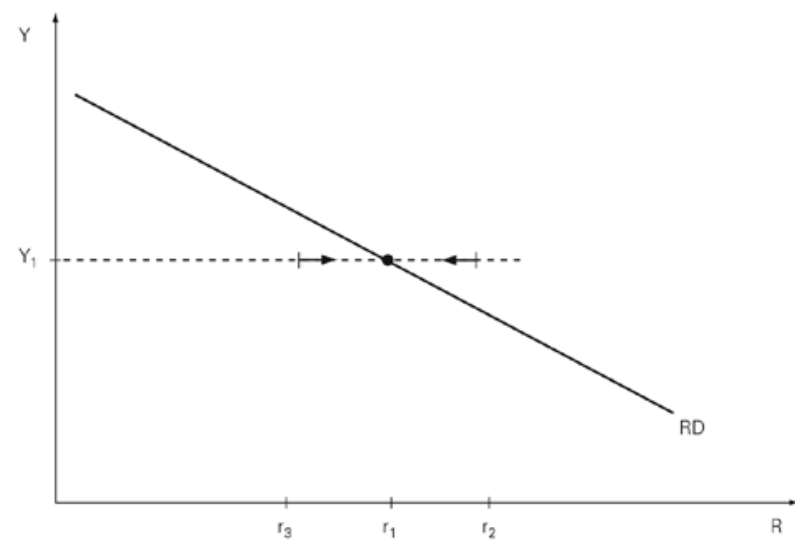

Como no gráfico anterior, no Gráfico 2 o desempenho econômico se mede no eixo vertical e a intensidade das reformas, no eixo horizontal. Suponhamos, nesse gráfico, que a economia esteja em y1, então a intensidade das reformas deverá ser 
igual a r1, ao longo da reta RD. Se, por acaso, a intensidade das reformas for maior do que isso, digamos $\mathrm{r} 2$, então, ao longo do tempo, conforme indicado pela seta na linha horizontal saindo de y1, supomos que o esforço reformista arrefecerá. Se, ao contrário, a intensidade das reformas estiver em r3, menor do que r1, ao longo do tempo as reformas se aprofundarão, conforme indicado pela outra seta na linha tracejada saindo de y1.

O Gráfico 3 junta as curvas YY e RD. Claramente, ocorre um equilíbrio de “economia política” no ponto M com coordenadas (y1, r1), pois aí há uma congruência entre o desempenho econômico y1 que resulta das reformas $\mathrm{r} 1$ - conforme medido pela relação YY - e a intensidade das reformas $r 1$ que resulta do desempenho econômico y1 - conforme medido pela relação RD.

\section{Gráfico 3: Economia e Reformas com Governo de "Direita"}

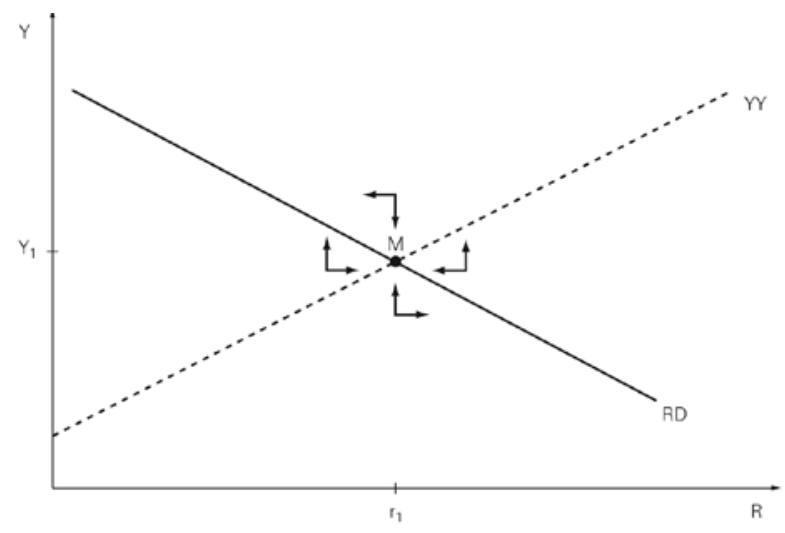

Ademais, conforme sugerido pelo jogo de setas (que está conforme às setas indicadas nos dois gráficos anteriores), em torno desse ponto $\mathrm{M}$, trata-se de um equilíbrio estável. A partir de qualquer outro ponto no gráfico há uma tendência de a economia e as reformas convergirem para $\mathrm{M}$.

Exatamente o que quer dizer o ponto $\mathrm{M}$, em termos de qualidade do desempenho econômico e intensidade das reformas, não é possível deduzir dessa exposição meramente qualitativa. Para nossos propósitos, entretanto, e tendo em vista a experiência brasileira recente, vamos qualificar o resultado $\mathrm{M}$ como sendo mediano - algumas reformas, com desempenho econômico razoável. Nada desastroso, nem muito brilhante.

\section{RESPOSTA DAS REFORMAS À ECONOMIA COM GOVERNO DE "ESQUERDA"}

O caso de um governo de "esquerda" é mais interessante. Vamos supor que não se trata de um governo socialista tradicional, que teria chegado ao poder por 
uma margem mínima de votos, graças a uma divisão do eleitorado entre três candidatos igualmente competitivos, como no caso de Allende no Chile, ou graças à força eleitoral de uma ampla coalização de esquerda, como Mitterrand na França. Trata-se, ao contrário, de um governo eleito com ampla maioria, a partir de um programa reformista moderado e em aliança com frações importantes do que acima denominamos de "centrão". Em tonalidades distintas, trata-se dos casos de Felipe Gonzales na Espanha, Tony Blair na Inglaterra e Lula no Brasil.

Tal tipo de governo não se defronta com uma oposição férrea no Congresso para fazer passar reformas dita neoliberais. Ao contrário, a oposição, ainda que tomada de surpresa pela mudança de postura dos novos governistas, e apesar dos fogos de artifício de rigor eleitoral, não poderá negar seu apoio às "suas” reformas. O "centrão", embora sempre arredio, é pouco resistente aos encantos de cargos e verbas controlados pelo governo. Como ensina o folclore político mineiro, há três coisas na frente das quais um político esperto não fica: água morro abaixo, fogo serra acima e governo federal.

Por outro lado, em contraste com a situação anterior de um governo de "direita", será difícil, com um governo de "esquerda", convencer o centrão a votar reformas com base nos riscos institucionais de uma situação econômica ruim, pois a seus olhos o pior que poderia acontecer para a estabilidade do sistema já ocorreu, com a vitória da "esquerda". Ou seja, no caso de um governo de "esquerda", o centrão pode ou não votar a favor das reformas, independentemente da situação econômica.

O problema é a própria base política do governo, conforme ilustrado pelos famosos "backbenchers" do trabalhismo inglês. Para convencê-los, a liderança do governo precisa mostrar resultado, a saber, desempenho econômico positivo (que em tese vai garantir um novo sucesso eleitoral mais à frente). Sempre há a tentação do populismo econômico ${ }^{2}$, conforme defendido no recente manifesto da "agenda interditada”, mas essa tentação é temperada por duas circunstâncias. Por um lado, o poder de fogo contrário dos mercados financeiros globalizados. Por outro, a percepção, pela liderança reformista, depois da evidência de tantos fracassos na América Latina, de que os bons resultados que o populismo pode gerar a curto prazo tornam-se péssimos a médio prazo - conforme ilustrado, no Brasil, pelo plano Cruzado no governo Sarney e, no Peru, pelo plano Inti, no governo Alan Garcia. Se as eleições nacionais estão ainda quatro anos à frente, essa percepção é um impedimento poderoso à tentação do populismo.

Essa discussão sugere que, num governo de "esquerda" reformista, tende a existir uma relação positiva entre a intensidade das reformas, $\mathrm{R}$, e o desempenho econômico, Y: quanto melhor estiver a economia, maior a autoconvicção e a capa-

\footnotetext{
2 Por populismo econômico, entende-se uma agenda de expansão monetária e fiscal, associada a controles de preços e restrições cambiais, destinados a reprimir temporariamente a inflação e o déficit no balanço de pagamentos.
} 
cidade política interna do governo para promover as reformas - que encontram pouca resistência no Congresso.

Além de positiva, que mais podemos dizer sobre essa relação? É plausível admitir que, para níveis baixos de desempenho econômico, quase nenhuma reforma é feita. A partir de um certo nível crítico de melhoria da economia, as reformas se aceleram. Para níveis muito altos de desempenho econômico, de novo, o empenho reformista se arrefece, pois há mais coisas para uma governo de "esquerda" fazer do que promover reformas de "direita" sem fim.

Isso sugere que, graficamente, a relação entre reformas e economia num governo de "esquerda" tenha a forma de um "S", como a curva RE no Gráfico 4: poucas reformas para níveis baixos de desempenho da economia; reformas aceleradas para níveis intermediários; e, novamente, poucas reformas na margem, para níveis elevados de desempenho ${ }^{3}$.

\section{Gráfico 4: Reformas - Função Positiva da Economia com Governo de "Esquerda"}

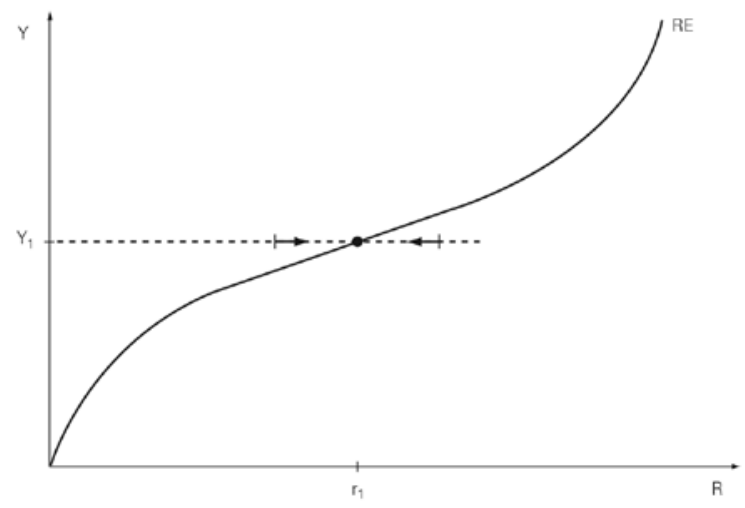

Para um dado desempenho econômico, digamos, y1 no Gráfico 4, os pontos à esquerda de RE indicam poucas reformas e, portanto, geram uma tendência de elas aumentarem de intensidade, conforme indicado pela direção da primeira seta na linha horizontal a partir de y1. Pontos à direita de RE indicam muitas reformas para o nível de desempenho econômico e, portanto, geram uma tendência de elas se reduzirem, conforme indicado pela direção da segunda seta na linha tracejada a partir do ponto y1. Em r1, a intensidade das reformas está equilibrada com o desempenho econômico y1.

\footnotetext{
${ }^{3}$ A curva RE parte da origem apenas por conveniência. Os resultados que se seguem se manteriam intactos caso supuséssemos que haveria um esforço reformista mínimo positivo mesmo com Y nulo.
} 


\section{EQUILÍBRIOS MÚLTIPLOS ENTRE ECONOMIA E REFORMAS...}

Resta juntar a relação YY, que liga a economia às reformas, à relação RE, que liga as reformas à economia sob um governo de "esquerda". Isso é feito no Gráfico 5 , que expressa a possibilidade particularmente interessante de equilíbrios múltiplos $^{4}$. Como se vê no gráfico, é possível haver três pontos de equilíbrio, P (para péssimo/ruim), $\mathrm{M}$ (para médio) e B (para bom/ótimo).

\section{Gráfico 5: Economia e Reformas com Governo de "Esquerda"}

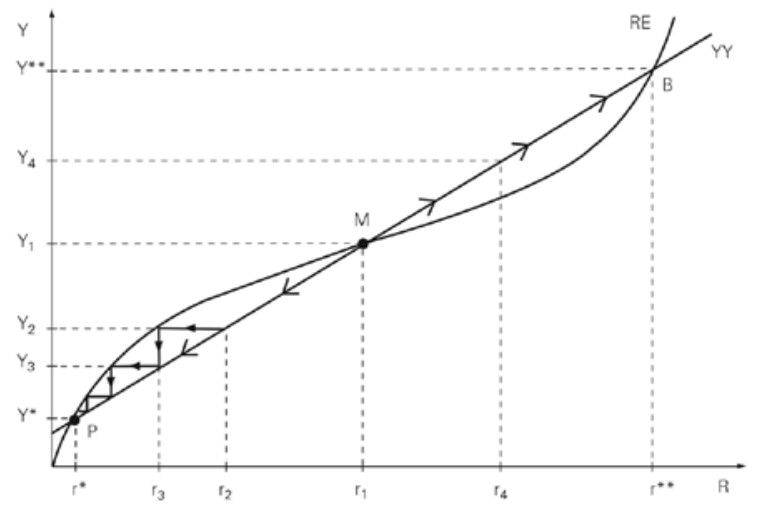

$\mathrm{Na}$ forma em que as curvas foram traçadas, e dadas as dinâmicas fora do equilíbrio anteriormente descritas, pode verificar-se que o equilíbrio em M é instável — qualquer afastamento dele, para cima, gera um "círculo virtuoso" em direção a B e, para baixo, gera um "círculo vicioso" em direção a P.

Já os equilíbrios em P e B são estáveis: pequenos afastamentos geram uma tendência de volta para eles. Por exemplo, suponhamos que a intensidade das reformas seja inicialmente dada por $\mathrm{r} 2$; isso gera um desempenho econômico igual a y2, ao longo da curva YY. Mas esse desempenho econômico é consistente com um volume de reformas $\mathrm{r} 3$ menor do que $\mathrm{r} 2$, ao longo da curva RE. Mas, se as reformas forem apenas $\mathrm{r} 3$, o desempenho econômico será y3, menor que y2, e assim por diante, numa espiral descendente até alcançar-se o ponto $\mathrm{P}$, com reformas igual a $\mathrm{r}$ * e desempenho econômico igual a $\mathrm{y}^{*}$.

Para ajudar a fixar idéias, no Gráfico 5 supomos que o ajustamento da econo-

\footnotetext{
${ }^{4}$ Os equilíbrios múltiplos são uma possibilidade, não uma certeza. Para ver isso imagine uma rotação suficiente forte para baixo da curva YY (menor recompensa econômica por unidade adicional de esforço de reformas): somente restaria o equilíbrio ruim. Alternativamente, se a curva YY fizesse uma rotação suficientemente forte para cima (maior resposta da economia a esforços adicionais de reforma), somente restaria o equilíbrio bom. Outras possibilidades de superação, respectivamente para pior ou para melhor, da situação de equilíbrios múltiplos seriam dadas por fortes rotações da curva RE para a esquerda (menos reformas para um mesmo Y) ou para a direita (mais reformas para um mesmo Y). Voltamos a esses temas na seção 8 .
} 
mia às reformas seja muito rápido, de modo que todos os pontos empiricamente observáveis estejam na curva YY. As setas ao longo dessa curva mostram como o sistema se move ao longo do tempo, dependendo do ponto inicial em que a economia se encontre, ao longo de YY.

Em resumo, ao contrário de um governo de "direita”, que se estabiliza numa situação mediana, um governo reformista de "esquerda" ou dá muito certo ou dá muito errado.

\section{PARA SUPERAR O APRISIONAMENTO NUM EQUILÍBRIO RUIM}

Vamos imaginar que, devido a um choque adverso, o governo de "esquerda" parta de uma situação econômica muito deteriorada - a chamada "herança maldita": por exemplo, um ponto abaixo de y* no Gráfico 5. Nesse caso, haverá um movimento reformista moderado, que fará a renda se elevar até y*, o que é compatível com uma intensidade de reformas $\mathrm{r}^{*}$. Assim, após uma pequena euforia (dada pelo movimento até $\mathrm{y}^{*}$ ), a situação se assentará no equilíbrio ruim $\mathrm{P}$, em tese pior do que o equilíbrio do governo de direita anterior (aqui representado pelo ponto $\mathrm{M}$ - só que agora, sob um governo de esquerda, esse ponto não é sustentável).

Com o país aprisionado num equilíbrio ruim sob um governo de "esquerda" reformista, há duas possibilidades de superação. A primeira é sorte - um forte choque favorável, ainda que temporário, no desempenho econômico, causado, por exemplo, por uma súbita e acentuada melhoria da situação econômica internacional. Esse choque favorável faria com que $\mathrm{Y}$ saltasse de $\mathrm{y}^{*}$ para, digamos, y4, acima do ponto crítico y1, o que levaria a um grande esforço reformista e à conseqüente instalação de um círculo virtuoso que levaria o país para o bom equilíbrio em $\mathrm{B}$ com coordenadas $\left(\mathrm{y}^{* *}, \mathrm{r}^{* * *}\right)$.

$\mathrm{Na}$ falta de um forte choque externo favorável, a única maneira de superar o equilíbrio ruim seria por meio de um "choque" político interno positivo, ou seja, um esforço reformista extraordinário que, independentemente do desempenho econômico, levasse a intensidade das reformas de $\mathrm{r}$ " para a direta do ponto crítico $\mathrm{r} 1$, por exemplo, r4. Esse esforço seria recompensado por uma grande melhoria da situação econômica, introduzindo então um círculo virtuoso de reformas e bom desempenho econômico que levaria o país para o bom equilíbrio B.

Onde nos encontramos no momento? As reformas previdenciária e tributária propostas pelo governo Lula são mais profundas do que aquelas contempladas no governo FHC, bem como são bons os prenúncios da lei de autonomia do Banco Central, da lei de falências e da reforma trabalhista. Por outro lado, a privatização (por exemplo, dos bancos estaduais remanescentes, dos aeroportos e do sistema de águas e esgotos) está parada, a autonomia das agências reguladoras está em risco, a nova regulamentação do setor elétrico permanece obscura, pouco se fez na área de segurança urbana e os MSTs estão à solta no campo e nas cidades.

Embora a direção geral esteja certa, o conjunto de reformas até o momento 
parece insuficiente para gerar um espetáculo de crescimento, como quer o presidente Lula (embora maior do que aquele indicado por $\mathrm{r}^{*}$ no Gráfico 5, o atual esforço de reformas seria inferior ao nível crítico $\mathrm{r} 1$, no mesmo gráfico - sendo igual a, digamos, r2). Visto de hoje, o mais provável é que a economia não responda tão positivamente quanto o governo Lula espera, o que, se a dinâmica exposta no Gráfico 5 estiver correta, levaria a um arrefecimento do ânimo reformista, fazendo com que a economia se estabilizasse num ponto como P.

\section{A HERANÇA MALDITA E A LUA-DE-MEL}

Dois importantes fatores da cena brasileira foram deixados de lado na análise anterior. $\mathrm{O}$ primeiro é favorável à convergência para um bom equilíbrio: dada a política macroeconômica prudente que se vem implantando, o desempenho da economia deve melhorar ao longo do tempo, independentemente do curso das reformas.

Analiticamente, uma maneira simples de expressar esse fator é tratar a relação entre desempenho econômico e reformas de uma forma dinâmica, incluindo o desempenho econômico do período anterior como um determinante adicional do desempenho econômico deste período. Assim, um dado esforço de reformas teria, até certo ponto, uma retribuição de desempenho econômico crescente ao longo do tempo ${ }^{5}$. Isso faria a reta YY no Gráfico 5 se deslocar paulatinamente para cima, com a passagem do tempo, o que levaria os pontos de equilíbrio $\mathrm{P}$ e $\mathrm{B}$ a se moverem para a direita. Caso o deslocamento da curva YY para cima fosse suficientemente forte, isso poderia inclusive levar a uma situação de um só (bom) equilíbrio no encontro das curvas YY e RE.

Contrapondo-se a esse fator positivo, que poderia vir da economia, há um fator possivelmente negativo, provindo da política, a saber, a evolução da popularidade do Presidente Lula. Sobre esse assunto, o melhor é passar a palavra a Bolívar Lamounier, em e-mail ao autor:

"Subjacente à formalização, acha-se a hipótese de que o apoio popular a Lula como presidente se manterá elevado, ou suficientemente elevado, pelo período para se aprovarem as reformas. Vale dizer, o que determina a intensidade das reformas não é apenas a lógica de aprisionamento mútuo entre a esquerda que tem de apoiar o 'seu' presidente e a direita que tem que votar as 'suas' reformas, mas também o cacife político individual

\footnotetext{
${ }^{5}$ Analiticamente, suponha-se uma relação $Y Y$ do tipo $y(t)=a+b r+c y(t-1)$, em que $y(t)$ é o desempenho econômico atual, $\mathrm{y}(\mathrm{t}-1)$, o desempenho econômico anterior e $\mathrm{r}$, a intensidade das reformas (que supomos constante ao longo do tempo); e em que a, b e c são constantes positivas e "c" é menor do que um. Então, no longo prazo, quando o valor de y se estabilizar (ou seja, $y(t)=y(t-1)=y$ ), a relação $Y Y$ será: $\mathrm{y}=((1 /(1-\mathrm{c}))(\mathrm{a}+\mathrm{br})$. Por exemplo, se $\mathrm{c}=0,5$, o impacto das reformas sobre o desempenho econômico será, no longo prazo, duas vezes maior do que no curto prazo, já que $1 /(1-c)=2$.
} 
do presidente. Sofisticando um pouco mais, cacife este suficiente para aprovar um primeiro conjunto de reformas (i.e., previdência), com o qual outro capital político será gerado, e assim se poderá trocar alguma popularidade perdida por esse outro capital, e assim sucessivamente. Essa hipótese parece plausível, de um lado, porque o nível de popularidade do momento ainda é típico de lua-de-mel, de outro, porque a primeira proposta de reforma foi elaborada rapidamente. Plausível também porque, ao contrário do apoio a Fernando Henrique, que era só 'economia', o apoio a Lula é 'economia + antropologia'.

"Mas não podemos descartar totalmente a hipótese de uma deflação abrupta, ou seja, de uma perda acentuada de popularidade num prazo mais curto do que o de tramitação da reforma 'crítica' (aquela que permite a primeira troca de popularidade por outro capital político). Por que não? (1) A 'herança maldita' está ficando e sendo percebida como bem maldita mesmo, com a economia arrochada; (2) a lógica de aprisionamento mútuo entre direita e esquerda, até aqui tratada pelo seu lado positivo, uma vez que torna cativo o apoio de quase toda a esquerda e boa parte da direita ao presidente, tem um pé de barro, que é a percepção de estelionato eleitoral, oportunismo, fazer reformas sem convicção, falta de 'accountability', enfim qualquer combinação desses elementos; (3) mais amplamente, vivemos numa sociedade na qual, a médio e longo prazos, os elementos secularizados, individualistas e instrumentais preponderam sobre os religiosos, comunitários e orgânicos; sociedade, portanto, na qual mesmo esse apoio 'antropológico' a Lula pelo que ele simboliza, por suas origens etc, pode hipoteticamente sofrer abrupta erosão.

"Neste cenário, a popularidade elevada, que é o grude ou um dos principais grudes responsáveis por colar os outros elementos, sofre queda acentuada antes da tramitação da reforma crítica; a economia, em ritmo de herança maldita, permanece maldita, ou fica mais maldita; e o aprisionamento mútuo entre direita e esquerda se arrefece (como vimos na previdência: bastou o funcionalismo público fazer uma primeira ameaça de greve e o governo saiu correndo para substituir o projeto, e o fez atabalhoadamente).

"Em conclusão, como fatores determinantes para os próximos meses, colocar-se-iam: (a) o desempenho da economia indicado especificamente pela política monetária (sensação de arrocho aumentando ou diminuindo); (b) a efetividade do processo de reforma, isto e, a capacidade de executar os primeiros passos, a saber, a reforma 'crítica', dentro de um horizonte plausível de tempo; (c) a popularidade de Lula.”

No contexto do Gráfico 5, poderíamos tentativamente resumir esse argumento supondo que, antes de o governo conseguir fazer um esforço crítico de reformas dado por $\mathrm{r} 1$, a popularidade do presidente Lula cairia e com isso se reduziria a 
base de apoio para reformas adicionais. A conseqüência seria uma rotação da curva RE para a esquerda e para cima (menos reformas para um dado desempenho econômico), de forma que se inviabilizasse o alcance do bom equilíbrio em $\mathrm{B}$, e somente mantendo a alternativa de um equilíbrio ruim à esquerda do ponto $\mathrm{P}$.

\section{À GUISA DE CONCLUSÃO}

A conclusão, pois, volta à sugestão de Bolívar Lamounier que deu origem à nota: o sucesso ou fracasso do governo Lula repousa no resultado de uma corrida entre a melhoria da economia, de um lado, e a evolução da popularidade do presidente, de outro.

A alternativa a essa situação de incerteza seria a formação de uma coalizão política efetivamente comprometida com as reformas, que juntasse a "esquerda" reformista com a "direita" esclarecida, permitindo ao governo ganhar em qualificação e libertar-se tanto do "centrão", como de seus próprios radicais.

Mas isso é conversa para depois das eleições municipais de 2004. 